Article

\title{
Novel Thermal Desalination Brine Reject-Sewage Effluent Salinity Gradient for Power Generation and Dilution of Brine Reject
}

\author{
Ali Altaee *(B) and Nahawand AlZainati \\ School of Civil and Environmental Engineering, University of Technology Sydney, Ultimo, NSW 2007, Australia; \\ nahawand.alzainati@student.uts.edu.au \\ * Correspondence: ali.altaee@uts.edu.au; Tel.: +61-420-606-500
}

Received: 12 March 2020; Accepted: 4 April 2020; Published: 6 April 2020

check for updates

\begin{abstract}
Salinity gradient resource presents an essential role for power generated in the process of pressure-retarded osmosis (PRO). Researchers proposed several designs for coupling the PRO process with the desalination plants, particularly reverse osmosis technology for low-cost desalination but there is no study available yet on the utilization of the concentrated brine reject from a thermal desalination plant. This study evaluates the feasibility of power generation in the PRO process using thermal plant brine reject-tertiary sewage effluent (TSE) salinity gradient resource. Power generation in the PRO process was determined for several commercially available FO membranes. Water flux in Oasys Forward Osmosis membrane was more than $31 \mathrm{~L} / \mathrm{m}^{2} \mathrm{~h}$ while the average water flux in the Oasys module was $17 \mathrm{~L} / \mathrm{m}^{2} \mathrm{~h}$. The specific power generation was higher in the thin film composite (TFC) membranes compared to the cellulose triacetate (CTA) membranes. The specific power generation for the Oasys membrane was $0.194 \mathrm{kWh} / \mathrm{m}^{3}$, which is $41 \%$ of the maximum Gibbs energy of the brine reject-TSE salinity gradient. However, the Hydration Technology Innovation CTA membrane extracted only $0.133 \mathrm{kWh} / \mathrm{m}^{3}$ or $28 \%$ of Gibbs free energy of mixing for brine reject-TSE salinity gradient. The study reveals the potential of the brine reject-TSE salinity gradient resource for power generation and the dilution of brine reject.
\end{abstract}

Keywords: pressure retarded osmosis; Pressure Retarded Osmosis-Multi Stage Flushing system; renewable energy; blue energy; membrane for power generation

\section{Introduction}

Renewable energy by mixing solutions of different concentrations have been investigated for power production by retarded pressure osmosis (PRO) technology [1,2]. The theory of the PRO process dates back to the sixties, to harvest the mixing energy of two solutions having different osmotic pressures. When a special membrane separates two solutions of different salinities and osmotic pressure, freshwater transports from the low to the high concentration solution due to the difference in the osmotic pressures [3]. The concentrated solution is partially pressurized before pumping in the PRO membrane to serve as the draw solution in the PRO process. The low concentration feed solution will be on the other side of the PRO membrane. The chemical potential transforms into a hydraulic pressure when the freshwater passes across the PRO membrane. Different designs and hybrid systems were suggested to increase the energy output in the PRO process [4-6]. Selecting a proper salinity gradient is critical for a successful PRO process. For example, the seawater-river water salinity gradient was found to be inappropriate for the PRO process since the energy input is larger than the energy yield of the salinity gradient [7]. PRO coupling with reverse osmosis (RO) process was extensively studied to reduce the cost of desalination $[1,5]$. The concentration of $\mathrm{RO}$ brine is twice 
that of seawater, and when coupled with a treated sewage effluent for power generation in the PRO process, it can yield maximum power equal to $0.19 \mathrm{kWh} / \mathrm{m} 3$. Researchers also evaluated potential power generation from mixing Dead Sea solution with seawater or RO brine [2,8]. Gibbs energy of mixing for Dead Sea brine-seawater salinity gradient is about $1.25 \mathrm{kWh} / \mathrm{m} 3$, indicating the potential of such salinity gradient when coupled for power production. Despite extensive efforts made to investigate the practicability of the PRO process of several salinity gradient resources, studies on coupling brine-reject from a thermal desalination plant with a tertiary treated sewage effluent (TSE) are scarce. TSE is tertiary treated for the removal of organic matters and nutrients from wastewater before discharge and would be a candidate feed solution.

Researchers have studied PRO hybridization with RO desalination in an effort to reduce the cost of desalination. Altaee and co-workers suggested a hybrid reverse osmosis-pressure retardrd osmosis (RO-PRO) process that can increase the recovery rate of the $\mathrm{RO}$ desalination and reduce the discharge of $\mathrm{RO}$ brine [2]. The power density of the $\mathrm{PRO}$ process using $\mathrm{RO}$ brine- $5 \mathrm{M} \mathrm{NaCl}$ salinity gradient resource reached $28 \mathrm{~W} / \mathrm{m}^{2}$. Hasan et al. [9] suggested a RO desalination plant powered by the PRO process. The study showed an improved performance of the RO-PRO system at a lower RO recovery rate, higher flow rates. A study by Sphia and Amy [10] investigated factors limiting water flux in the PRO process in the RO-PRO system. Four membranes of different water and salt permeability were tested using a wastewater feed solution. Experiments showed that the power density of all tested membranes was similar due to membrane fouling and proposed that future work should focus on fouling mitigation to improve the performance. In another study, optimization of power generation in a modular PRO membrane revealed that the optimized values of hydraulic pressure and flow rates in a laboratory-scale experiment are different from those in a full-scale PRO module [11]. The study recommended that module optimization helps to reduce the hydraulic pressure and feed/draw solution flow rate towards a higher PRO performance.

Researchers also investigated the effect of feed temperature on the performance of the PRO membrane when coupled with the RO desalination plant [12]. The investigation revealed that a reduced energy generation of the RO-PRO system is achievable at elevated hydraulic pressures, but that would compromise the permeation flow in the system. Accordingly, increasing the temperature of the feed solution would compensate declined water flux in the PRO process operating at high pressure. A techno-economic study performed by Mauricio et al. [13] found that coupling PRO with a RO desalination plant would save $9 \%$ of the desalination energy. The study suggested that the PRO process was able to reduce the salinity of the RO brine from around 66 to $41 \mathrm{~g} / \mathrm{L}$, hence reducing the environmental impact of the desalination process. Researchers also found that the membrane fouling is lower when the process operates in the forward osmosis mode (AL-FS) compared to the PRO mode (AL-DS). As such, the AL-FS mode offers a more sustainable PRO process when membrane fouling is a problem [14].

The current study theoretically evaluates the multi-stage flashing (MSF)-PRO process for sustainable desalination and energy generation. A computer model was applied to calculate water flux in the PRO membrane. Seawater desalination by the MSF technology is one of the conventional methods for freshwater supply in the regions of high seawater salinities. The MSF technology can handle high seawater salinities and produce freshwater of high quality [15]. Brine reject and TSE are paired in the PRO process to generate energy and dilutes the feed solution to the MSF plant (Figure 1). The MSF desalination technology is not considerably impacted by the salinity of feed solution but is sensitive to a high concentration of divalent ions in the feed solution, which leads to scale formation and deposition, mainly the deposition of $\mathrm{MgSO} 4$ and $\mathrm{CaSO} 4$. The formation and deposition of non-alkaline scale, $\mathrm{MgSO}_{4}$ and $\mathrm{CaSO}_{4}$, are adversely affecting the heat transfer efficiency of the MSF desalination plant and the energy requirements. In the proposed PRO-MSF system, divalent ions, which are problematic to the MSF plant, are diluted in the PRO process by the permeation flow. Therefore, mixing the diluted draw solution with feed water to the MSF plant will decrease the problem of scaling. The other advantage of coupling the PRO process with the MSF plant is osmotic pumping 
of the diluted brine exiting the PRO membrane to the MSF plant and hence, reducing the pumping energy to the MSF plant. It should be noted that the pumping energy of the brine reject contributes mainly to the high electric power consumption of the MSF plant. Four commercial FO membranes were evaluated as potential PRO membranes. The study considered a full-scale PRO module with matching physical dimensions to the Hydration Technology Innovation's (HTI) FO module, of $1 \mathrm{~m}$ length and $16.5 \mathrm{~m}^{2}$ active area, for the PRO process. The temperatures of the draw and feed solution were $40^{\circ} \mathrm{C}$ and $25^{\circ} \mathrm{C}$, respectively, to resemble the MSF brine reject and seawater temperature.

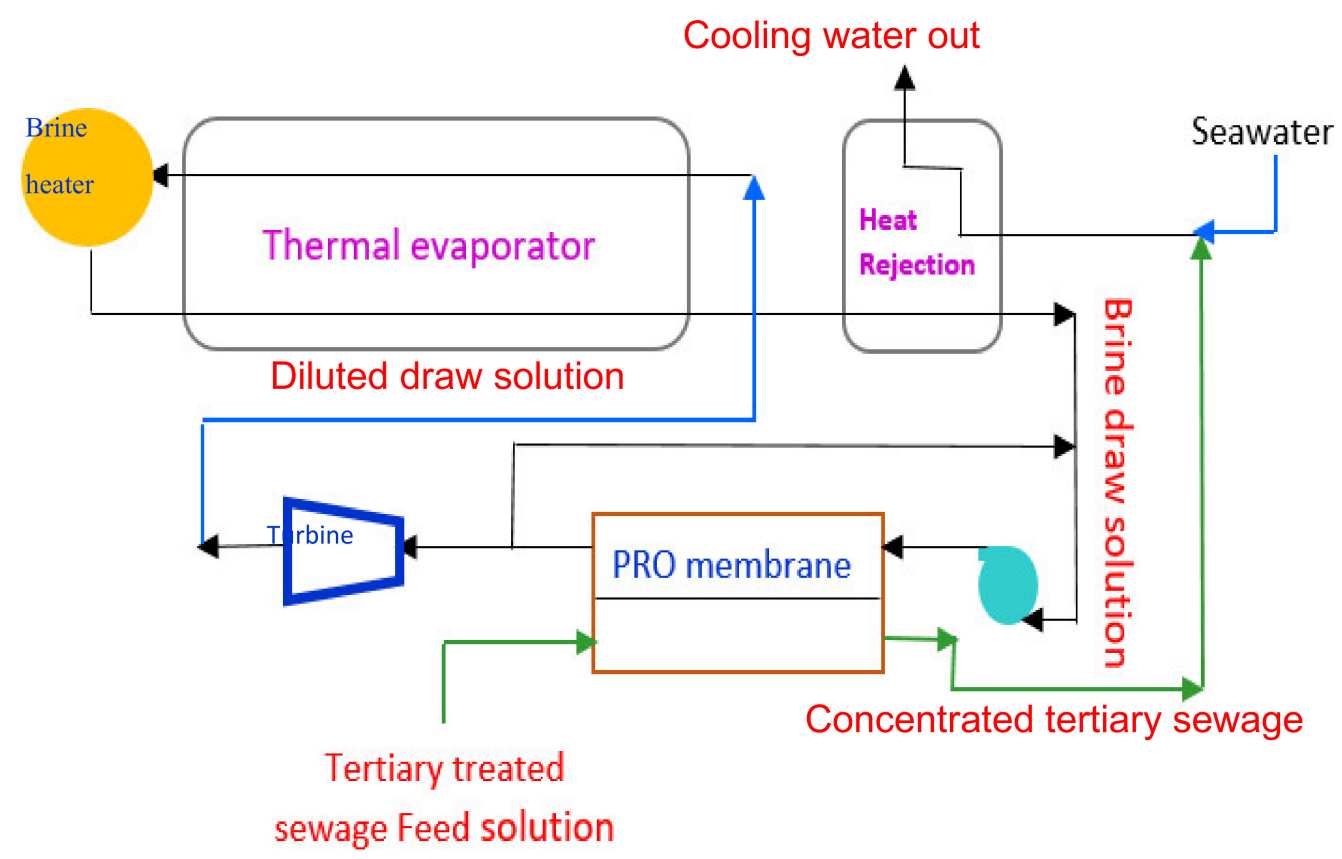

Figure 1. Pressure Retarded Osmosis-Multi Sstage Flushing hybrid system for power generation.

\section{Materials and Methods}

\subsection{MSF-PRO Hybrid System}

Multi-stage flashing (MSF) as one of the thermal processes is a standard technology for the desalination of seawater sources in many Middle Eastern countries. MSF technology has been in operation since the sixties and gained great credit for the capability to handle the harsh environmental conditions of seawater in the Middle East. Due to the salinity of seawater in the Middle East, the total dissolved solids (TDS) of the expelled brine from the MSF plant usually is about $80 \mathrm{~g} / \mathrm{L}, 1.37 \mathrm{M} \mathrm{NaCl}$ [15]. The salinity of seawater brine reject is higher than the salinity of seawater $(35 \mathrm{~g} / \mathrm{L})$, around 2.3 times higher, which provides tremendous osmotic power for the PRO process when coupled with a low salinity feed solution such as TSE, TDS $0.026 \mathrm{M} \mathrm{NaCl}(1.5 \mathrm{~g} / \mathrm{L})$ [7]. In addition to its high osmotic pressure, the temperature of brine reject's is always from $10^{\circ} \mathrm{C}$ to $15^{\circ} \mathrm{C}$ higher than seawater, which provides an additional advantage since both permeation flow and osmotic pressure of the membrane incline to increase when a higher feed solution's temperature occurs [15]. Coupling the brine reject with the TSE as a source of salinity gradient has a high prospect for generating power in the PRO as a result of its high osmotic energy. Additionally, brine reject and TSE are waste streams and are recognized as an environmental pollution source. Brine reject is paired with TSE in the PRO process, as depicted in Figure 1. TSE is circulated to the heat rejection unit after mixing with seawater to reduce the pumping energy of cooling water to the heat rejection unit. The purpose of the latter unit is to reduce the temperature of brine before discharge. Differently, diluted brine reject from the PRO process could be recycled with the feed stream into the MSF evaporator to reduce the scaling problem. It is expected that freshwater transporting across the PRO membrane would lower the concentration of the brine 
reject draw solution and reduce the divalent ions concentration. These ions are in charge of scale formation in the MSF plant. Freshwater movement across the membrane dilutes the concentrations of divalent ions in the draw solution. Recycling the diluted brine reject from the PRO process to the MSF plant will alleviate the occurrence of scale deposition. Accordingly, recycling the diluted brine reject to the MSF evaporator would decrease the cost of seawater pumping into the MSF plant and the use of antiscalants.

\subsection{PRO Membranes}

Most of the experimental studies used a FO-like membrane to produce power by the PRO process [16]. The rationale for using FO membranes is because osmotically driven membrane processes require a special membrane of thin structure parameter $(S)$ to reduce concentration polarization influences on the side of the support layer. The structure parameter (S) gives an indication to support the layer thickness of the membrane. Four commercial FO membranes of different water and salt permeabilities were evaluated for power production. Table 1 shows the characteristics of the membrane used in the computer model to calculate water flux in the PRO process [16-19]. In general, polyamide thin film composite (TFC) membrane such as Oasys, FTS membrane and Porifera showed at least two times higher water permeability than cellulose triacetate (CTA) membrane, while the membrane structure of TFC membranes was smaller than that of the CTA membrane which reduced the impact of concentration polarization. A smaller structure parameter is advantageous to reduce internal concentration polarization as in the Porifera TFC membrane [18]. However, HTI's CTA membrane tolerates higher chlorine concentrations than TFC membranes, making such a membrane suitable for use with low-quality feed solutions.

Table 1. Properties of the Forward Osmosis membrane utilized in the PRO process.

\begin{tabular}{ccccc}
\hline Membrane Type & $A w\left(\mathbf{L} / \mathbf{m}^{\mathbf{2}} \mathbf{h} \cdot \mathbf{b a r}\right)$ & $\boldsymbol{B}\left(\mathbf{L} / \mathbf{m}^{\mathbf{2}} \mathbf{h}\right)$ & $S(\boldsymbol{\mu})$ & Ref. \\
\hline Porifera Thin Film Composit & 2.1 & 1.2 & 344 & {$[17]$} \\
Oasys This Film Composit & 3.92 & 1.34 & 375 & {$[18,19]$} \\
Hydration Technology Innovation Cellulose triacetate & 0.627 & 0.733 & 663 & {$[17]$} \\
Fluid Technolgy Solutions Thin Film Composit & 1.25 & 0.19 & 471 & {$[16]$} \\
\hline
\end{tabular}

\subsection{Mathematical Model}

An advanced computer paradigm was used to estimate the flux of water in a full-scale PRO membrane of $1 \mathrm{~m}$ long and $16.5 \mathrm{~m}^{2}$ active area. The membrane dimensions are similar to those of HTI's spiral wound FO membrane. In this study, the FO module was divided into equal sections, and the water flux of each section was calculated. Water flux $\left(\mathrm{J}_{\mathrm{w}, \mathrm{s}}\right)$ along the PRO module was measured by Equation (1):

$$
J_{w, s}=A_{w}\left\{\frac{\left(\frac{n R T C_{D i, s}\left(1+\frac{Q_{D i, s}}{Q_{D o, s}}\right)}{2}\right) \exp \left(\frac{-J_{w, s}}{k_{d}}\right)-\left(\frac{n R T C_{F i, s}\left(1+\frac{Q_{F i, s}}{Q_{F o, s}}\right)}{2}\right) \exp \left(J_{w, s} K+\frac{J_{w, s}}{k_{f}}\right)}{1+\frac{B}{J_{w, s}}\left(\exp \left(J_{w, s} K-\frac{J_{w, s}}{k_{f}}\right)-\exp \left(\frac{-J_{w, s}}{k_{d}}\right)\right)}-\Delta P\right\}
$$

where, $n$ is the ions number in the mixture, $R$ is the ideal gas constant, $A_{w}$ is the coefficient of water permeability, B is the coefficient of salt permeability, $k_{d}$ and $k_{f}$ are draw and feed solutions mass transfer coefficients, respectively, $K$ is the solute resistivity for diffusion within the support layer, $C_{D i, S}$ is the inlet DS concentration at distance $s$ along the membrane channel, $C_{F i, s}$ is the inlet FS concentration at the distance $s$ along the membrane channel, $Q_{D i, s}$ and $Q_{D o, s}$ are the DS inlet and outlet flow rates, respectively, $Q_{F i, S}$ and $Q_{F o, s}$ are the FS inlet and outlet flow rates, respectively, $\Delta P$ is the difference of hydraulic pressure through the membrane, and $T$ is the temperature in Kelvin. More details about Equation (1) derivation can be checked in the literature [7]. 
Power density in the PRO system is a function of hydraulic pressure multiplied by permeate flow rate. In a full-scale PRO membrane, power density along the membrane, $W x$, is found by using the next expression [7]:

$$
W_{x}=P \cdot J_{w, s}
$$

Here, $P$ is the DS hydraulic pressure. In this study, the energy output, $E_{s}$, across the PRO membrane was measured by Equation (3) and it is equal to the variation of maximum specific energies between inlet and outlet streams at any distance across the membrane [7]:

$$
E_{s}=\frac{n R T\left(C_{D i, s}-C_{F i, s}\right)^{2}}{4\left(C_{D i, s}-C_{F i, s}\right)}-\frac{n R T\left(C_{D o, s}-C_{F o, s}\right)^{2}}{4\left(C_{D o, s}-C_{F o, S}\right)}
$$

The current study evaluated the specific power creation in the PRO process for all membranes listed in Table 1. The concentrations of brine reject and TSE in the PRO process were $80(1.37 \mathrm{M}$ $\mathrm{NaCl})$ and $1.6 \mathrm{~g} / \mathrm{L}(0.026 \mathrm{M} \mathrm{NaCl})$, respectively $[7,15]$. The concentration of brine reject is based on the concentration of seawater in the gulf area of the Middle East. The temperature of brine reject was $40{ }^{\circ} \mathrm{C}$ while the TSE temperature was $25^{\circ} \mathrm{C}$. Solute resistivity for diffusion, $\mathrm{K}$, is the ratio of the membrane structural variable $(S)$ to the solute diffusion coefficient $(D)$, i.e., $K=S / D$. In this study, $D$ is equal to $\left(\sim 2.08 \times 10^{-9} \mathrm{~m}^{2} / \mathrm{s}\right)$ [20], and $S$ is from Table 1 . $k_{f}$ was assumed to be equal to $k_{d}, k_{d} \approx k_{f}$, and equal to $0.18 \mathrm{~m} / \mathrm{h}[1,5]$. The flow rate of the FS and DS was 486 and $3600 \mathrm{~L} / \mathrm{h}$, respectively.

\section{Results}

\subsection{Model Validation}

Data based on experiments done previously in a pilot plant research were used for validation of the computer model [6]. A full-scale hollow fibre PRO module (Toyobo, Japan) was used in the PRO unit for energy generation. The membrane is $682 \mathrm{~mm}$ long and comes with a $70.5 \mathrm{~m}^{2}$ membrane active area and $0.27 \mathrm{~L} / \mathrm{m}^{2} \mathrm{~h}$ and $0.035 \mathrm{~L} / \mathrm{m}^{2} \mathrm{~h}$.bar permeability coefficients of water and salt, respectively [6]. The flow rates and concentrations of DS and FS were 720 and $480 \mathrm{~L} / \mathrm{h}$ and $1 \mathrm{M} \mathrm{NaCl}$ and DI water, respectively. $K$ is the ratio of $S$ to the coefficient of salt diffusion $(D)$ of $\mathrm{NaCl}$, i.e., $K=S / D$. The structure variable $(S)$ of the hollow fibre membrane is $1024 \mu \mathrm{m}$ and $D$ for $1 \mathrm{M} \mathrm{NaCl}$ is $1.3 \times 10^{-9} \mathrm{~m}^{2} / \mathrm{s}$, and the $K$ value is $219 \mathrm{~h} / \mathrm{m}$ [6]. Water and solute permeabilities of the hollow fibre PRO membrane are $0.27 \mathrm{~L} / \mathrm{m}^{2} \mathrm{~h} . b a r$ and $0.035 \mathrm{~L} / \mathrm{m}^{2} \mathrm{~h}$, respectively. The mass transfer coefficient, $k$, is assumed to be $0.0137 \mathrm{~m} / \mathrm{h}$. Water flux in the PRO unit was calculated for a number of hydraulic pressures. Table 2 shows the testing conditions and PRO water flux, both experimentally and theoretically.

Table 2. Experimental and theoretical water flux in the PRO process using a hollow fibre PRO membrane.

\begin{tabular}{cccccccc}
\hline $\boldsymbol{P}_{\boldsymbol{D S}}(\mathbf{b a r})$ & $\boldsymbol{P}_{F S}(\mathbf{b a r})$ & $\boldsymbol{Q}_{D S}(\mathrm{~L} / \mathbf{h})$ & $\mathbf{Q}_{F S}(\mathbf{L} / \mathbf{h})$ & $\boldsymbol{\Delta P}(\mathbf{b a r})$ & $\begin{array}{c}J_{w-e} \\
\left(\mathbf{L} / \mathbf{m}^{2} \mathbf{h}\right)\end{array}$ & $\begin{array}{c}J_{w-t} \\
\left(\mathbf{L} / \mathbf{m}^{2} \mathbf{h}\right)\end{array}$ & \%Agreement \\
\hline 5 & 2.8 & 720 & 480 & 2.2 & 6.2 & 6.46 & $96.0 \%$ \\
11.5 & 2.9 & & & 8.6 & 5.5 & 5.3 & $96.4 \%$ \\
14.7 & 3 & & & 11.7 & 5.10 & 4.95 & $97.1 \%$ \\
17.5 & 3.4 & & & 14.1 & 4.75 & 4.58 & $96.4 \%$ \\
24 & 3.8 & & & 20.2 & 3.80 & 3.67 & $96.6 \%$ \\
\hline
\end{tabular}

The computer model results have shown good consistency between experimental water flux, $J_{w-e}$, and theoretical water flux $J_{w-t}$ (Table 2). There is $96.9 \%$ to $97.1 \%$ similarity of the experimental and theoretical data, showing that the computer model accurately predicted water flux in the PRO membrane. Figure 2 shows the results, there is excellent agreement between theoretical results and experimental ones. 


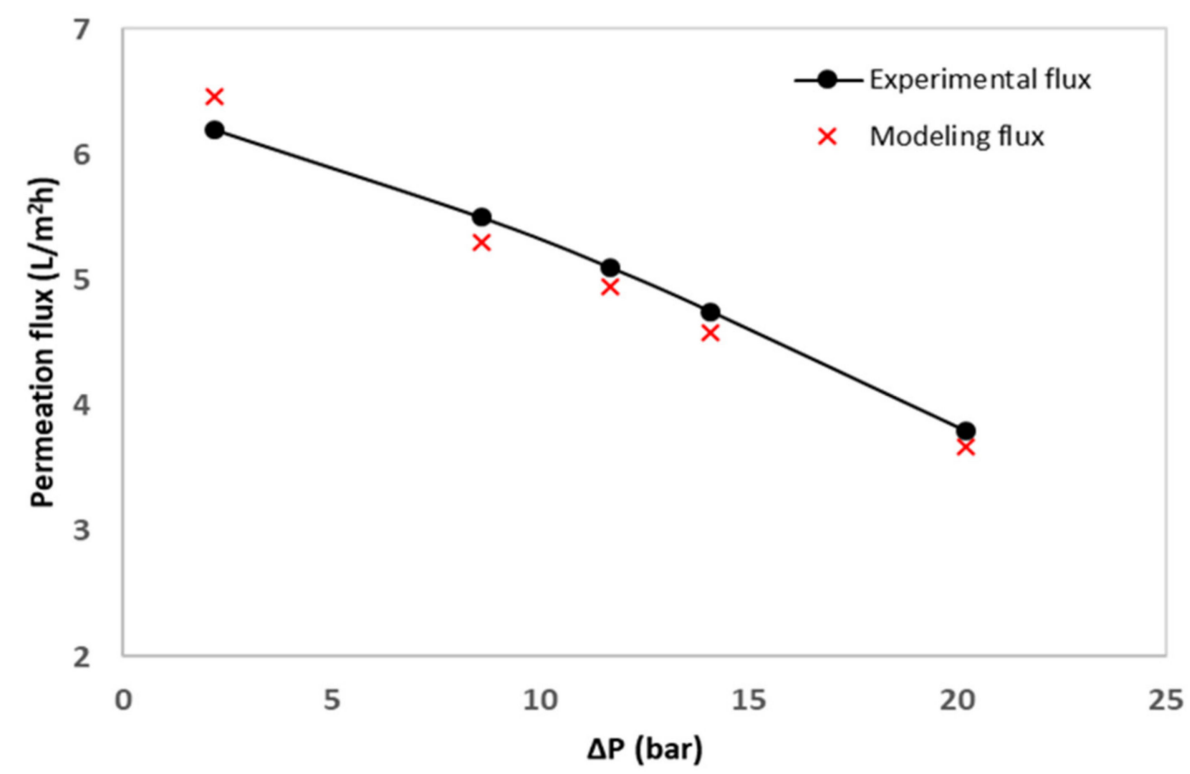

Figure 2. Theoretical and experimental water flux in the PRO process of $1 \mathrm{M} \mathrm{NaCl}$ DS and DI water FS.

\subsection{PRO Water Flux and Power Density}

Water flux in a full-scale PRO module can be estimated from Equation (1) for all FO membranes listed in Table 1 . In this study, $K$ was calculated as the ratio of $S$ (Table 1 ) to salt diffusion coefficient $\left(\sim 2.08 \times 10^{-9} \mathrm{~m}^{2} / \mathrm{s}\right)$ [20], while $k_{d}=k_{f}$ is $0.18 \mathrm{~m} / \mathrm{h}[1,5]$. Figure 3a shows that water flux, for all membranes, decreased along the PRO module due to the process of DS dilution by permeation flow from the feed side. Oasys membrane exhibited the highest water flux, $31 \mathrm{~L} / \mathrm{m}^{2} \mathrm{~h}\left(0.031 \mathrm{~m}^{3} / \mathrm{m}^{2} \mathrm{~h}\right)$, followed by the Porifera, TFS and HTI membranes, respectively. A previous pilot plant project by Yasuhiko et al. (2018) calculated the average water flux in the PRO module from dividing the total permeate flow in the module by the membrane area [6]. The average value of water flux in this study was the summation of water flux of all membrane sections along the FO module divided by the number of sections in the module [15]. Figure 3a shows that the average water flux of the Oasys, Porifera, TFS and HTI membranes were 18.7 (0.0187), $17(0.017), 15.6(0.0156)$, and $10.7(0.0107) \mathrm{L} / \mathrm{m}^{2} \mathrm{~h}$ $\left(\mathrm{m}^{3} / \mathrm{m}^{2} \mathrm{~h}\right)$, respectively. In general, TFC membranes demonstrated higher water flux than what was produced in the CTA membranes like HTI's TFC membrane. The results were in agreement with previous studies that showed water flux in the TFC membrane was higher than that in the CTA membrane [21,22]. Larger water flow in polyamide TFC membranes is also attributed to its thinner support layer compared to CTA membranes (Table 1). The membrane structure parameter plays a key role in controlling concentration polarization in osmotically impelled membrane processes. Thinner membranes are usually preferred in the osmotically driven membrane processes to reduce the influence of internal concentration polarization, which is more serious and difficult to control. As such, higher permeation flow could be achieved in the TFC membrane because of the lower impact of internal concentration polarization.

Power density for CTA and TFC PRO membranes was calculated and presented in Figure $3 \mathrm{~b}$. The hydraulic pressure in the $P R O$ process was 32 bar, based on $\Delta P=\Delta \pi / 2$ ratio that was recommended in previous studies to achieve maximum power density [23]. A power density of a maximum of 28.2 $\mathrm{W} / \mathrm{m}^{2}$ was obtained in the Oasys membrane, $25 \mathrm{~W} / \mathrm{m}^{2}$ in the Porifera membrane, $21.2 \mathrm{~W} / \mathrm{m}^{2}$ in the FTS membrane and finally, $12.9 \mathrm{~W} / \mathrm{m}^{2}$ in the HTI membrane. However, the average power density, which is the average power density of full-scale PRO membranes in Figure $3 \mathrm{~b}$, was $15.3 \mathrm{~W} / \mathrm{m}^{2}$ in the Porifera membrane, $14 \mathrm{~W} / \mathrm{m}^{2}$ in the FTS and finally, $9.59 \mathrm{~W} / \mathrm{m}^{2}$ in the HTI membrane. These power densities are higher than the value recommended for an economic PRO process and equal to $5 \mathrm{~W} / \mathrm{m}^{2}$. Unfortunately, this threshold value did not take into account the thermodynamic conditions of salinity gradient 
resources and hence, it needs to be confirmed to ensure that power input is less than power output to achieve an economic PRO process.

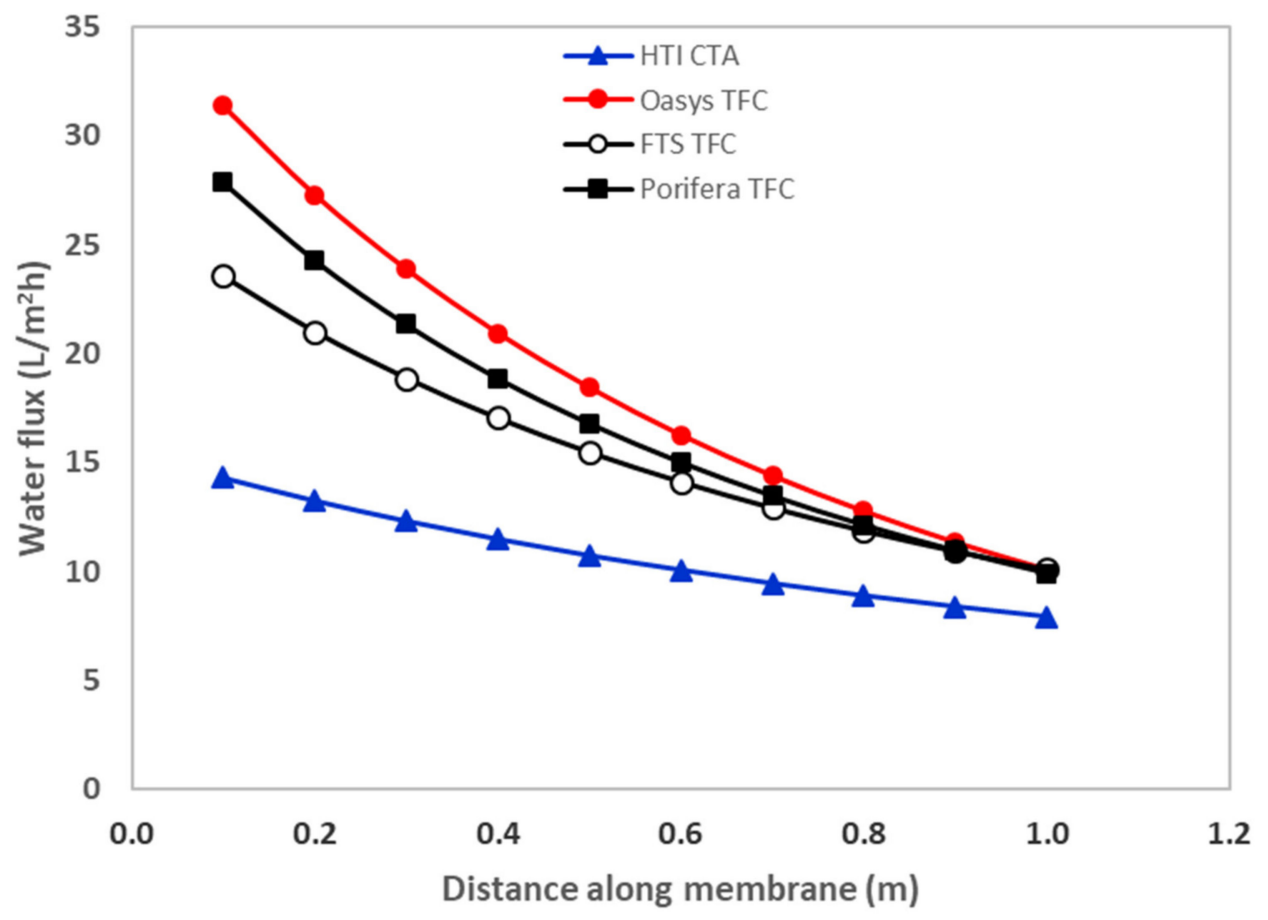

(a)

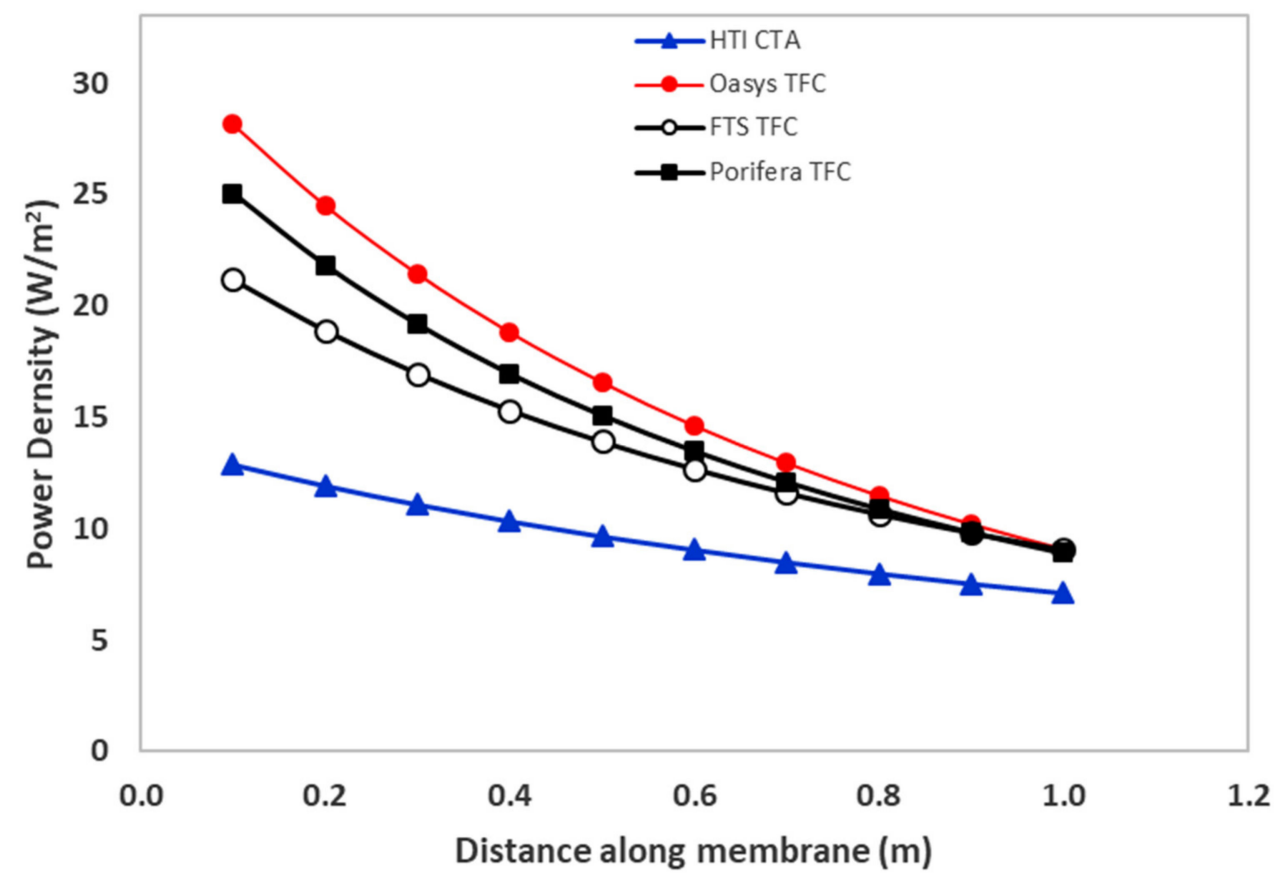

(b)

Figure 3. Water flux and power density in the PRO process for several PRO membranes.: (a) Water flux of the PRO module; (b) Power density of the PRO module. 


\subsection{Specific Power Consumption}

Specific power generation was found by calculating the maximum specific energy difference between inlet and outlet streams according to Equation (3). Figure 4 shows the profile of the specific power generation along the PRO module for all membranes investigated in the current study. The applied hydraulic pressure at the side of the DS brine reject is 32 bar, i.e., $\Delta P=\Delta \pi / 2$. The accumulative specific power production in the PRO module increased towards the end of the module for all membranes but was higher for the Oasys membrane. At the end of the PRO process, the specific power generated in the Oasys membrane was $0.194 \mathrm{kWh} / \mathrm{m}^{3}$ but decreased to $0.183,0.173,0.133 \mathrm{kWh} / \mathrm{m}^{3}$ for the Porifera, FTS, and HTI membranes, respectively. These specific power generations are, respectively, $41 \%, 39 \%, 0.37$, and $28 \%$ of the maximum Gibbs free energy of the brine reject-TSE salinity gradient resource, $0.47 \mathrm{kWh} / \mathrm{m}^{3}$. Indeed, this is the output energy from the PRO process and not the net power generation by the system.

The net power generation is the variation between the output and input energy values of the PRO process [7]. The energy input includes all energies used for pumping solutions, pre-treatments processes needed for feed and draw solutions, and losses. Our past study suggested that wastewater is already pretreated before discharge, and hence the energy required for wastewater treatment before pumping into the PRO membrane is $0.1 \mathrm{kWh} / \mathrm{m}^{3}$ [7]. We assumed that brine reject does not require pretreatment after leaving the MSF plant. There is an additional specific power consumption for pumping from source and it is equal to $0.03 \mathrm{kWh} / \mathrm{m}^{3}$. Pumping into the PRO module requires $1.5 \mathrm{bar}$, and that is equal to $0.05 \mathrm{kWh} / \mathrm{m}^{3}$. In this present study, an assumption that the efficiency of pressure exchanger (PX) is $98 \%$ was made, and hence, there will be $0.017 \mathrm{kWh} / \mathrm{m} 3$ energy loss in the PX system and applied pressure in the PRO process is 32 bar.

Results in Table 3 display energy input, energy output and net power that are generated in the PRO process. The total power generation in the PRO process using the HTI membrane is $0.133 \mathrm{kWh} / \mathrm{m}^{3}$, this is lower than the energy input in the PRO process. Consequently, the HTI membrane performance is considered unsatisfactory in the PRO process using brine reject-TSE salinity gradient resources. The Oasys membrane achieved the highest net power generation and it was $0.047 \mathrm{kWh} / \mathrm{m}^{3}$. For the Porifera membrane, the net power generation was $0.036 \mathrm{kWh} / \mathrm{m}^{3}$ while it was about $0.026 \mathrm{kWh} / \mathrm{m}^{3}$ for the FTS membrane. Apart from the HTI membrane, the net power generation was promising for all membranes. Figure 3B demonstrates the power generation in the PRO process for different membranes compared to the energy input for brine reject-TSE salinity gradient. It is obvious that most of the PRO membranes, apart from HTI, were able to produce higher energy than energy input in the PRO process with the Oasys membrane leading the performance of the membranes. The net power generation was 32\%, $24 \%$ and $18 \%$ higher than the energy input for the Oasys, Porifera, and FTS membranes, respectively. In practice, most of the MSF desalination plants have large capacities for freshwater supply to large cities and communities in the GCC countries. Assuming that the average MSF desalination plant generating over $100,000 \mathrm{~m}^{3} /$ day of brine reject at $40{ }^{\circ} \mathrm{C}$, a net specific power generation of $4700 \mathrm{~kW}$ could be achieved in the PRO process using the Oasys membrane (assuming that the net power generation in the Oasys membrane is $0.047 \mathrm{kWh} / \mathrm{m}^{3}$ ). Using PRO membranes of lower water permeabilities such as the Porifera and FTS membranes, the net specific power generation is $3600 \mathrm{~kW}$ and $2600 \mathrm{~kW}$, respectively. The results illustrate the great potential of the PRO process using brine reject-TSE salinity gradient resources for power generation in the region of the Middle East.

It should be mentioned that the PRO performance, in reality, could be even better when real brine reject is applied as the draw solution. The high temperature of the brine reject, $40{ }^{\circ} \mathrm{C}$, will promote water flux in the PRO membrane. Experimental work on the forward osmosis process using MSF brine reject draw solution revealed that over $30 \%$ increase in water flux was achieved by increasing the temperature of brine reject draw solution from $25^{\circ} \mathrm{C}$ to $40^{\circ} \mathrm{C}$ [15]. Therefore, the PRO process performance, in reality, is expected to be higher than that reported in this study. 


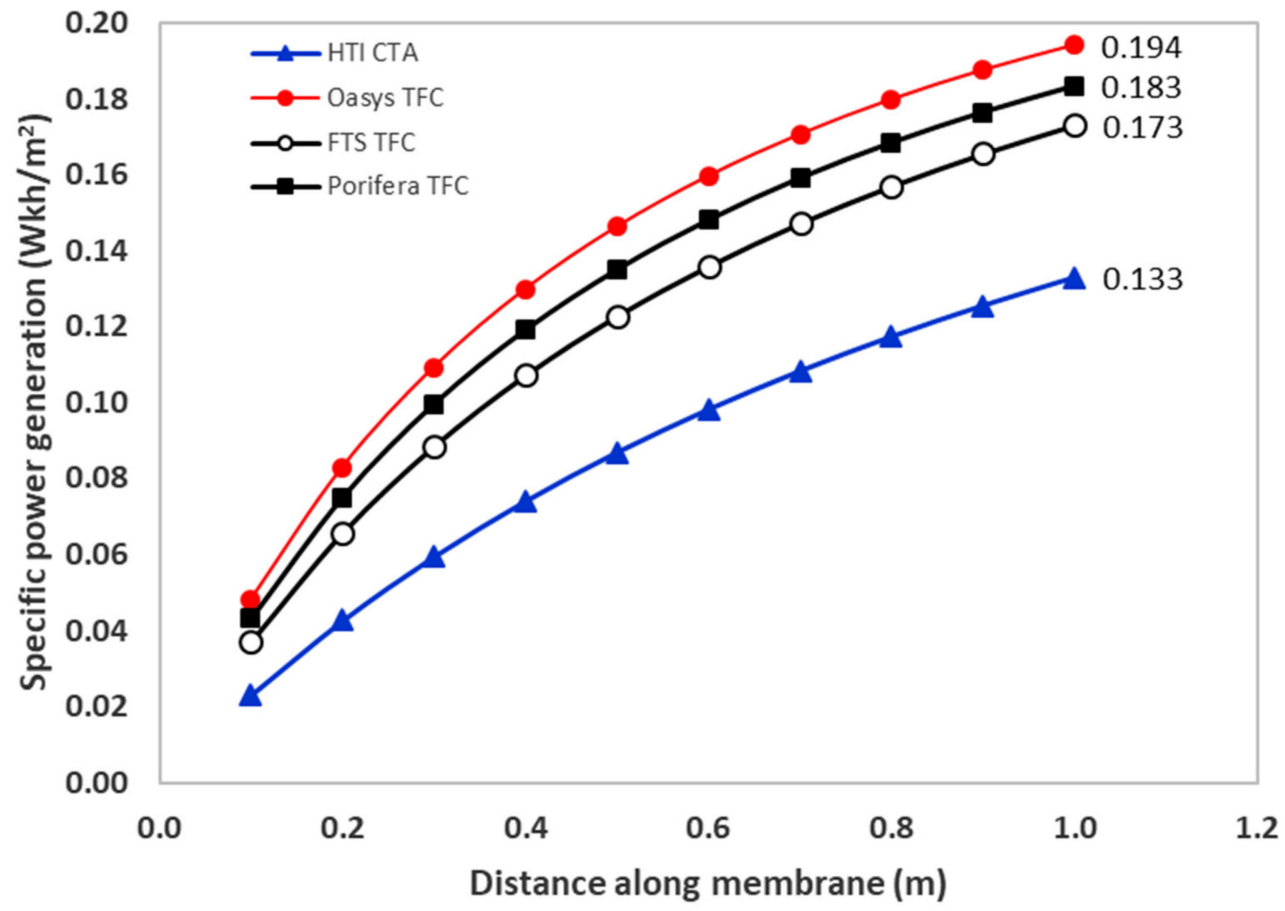

(a)

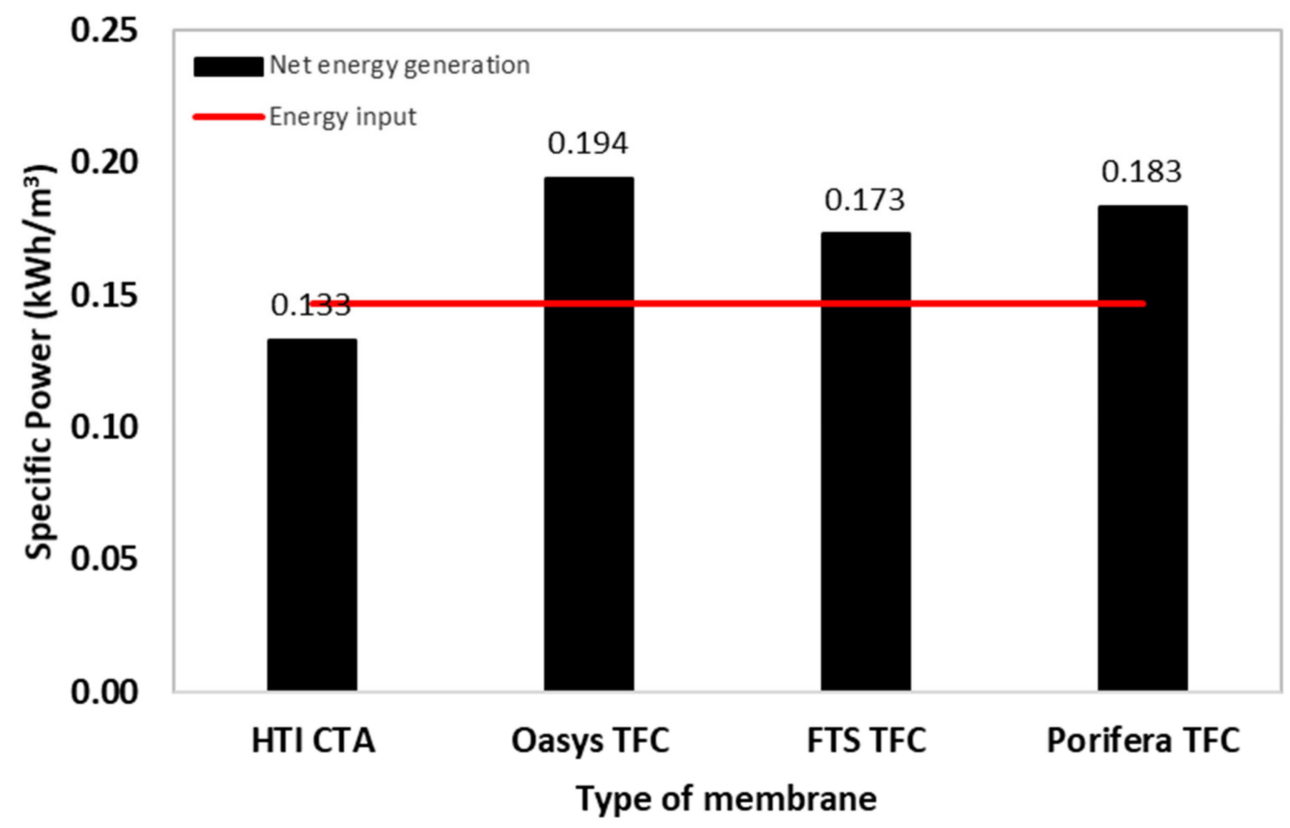

(b)

Figure 4. Specific power generation by different membranes: (a) Specific power generation in the PRO process for brine reject-TSE salinity gradient resource; (b) Net power generation and energy input in the PRO process for all PRO membranes. Concentrations of brine reject and TSE are 1.37M and $0.03 \mathrm{M} \mathrm{NaCl}$, respectively. 
Table 3. Energy input, energy output and net power generation for different PRO membranes using brine reject-TSE salinity gradient.

\begin{tabular}{ccc}
\hline & \multicolumn{2}{c}{ Energy $\mathbf{k W} / \mathbf{m}^{\mathbf{3}}$} \\
\cline { 2 - 3 } Process Description & Brine Reject-Wastewater & Net Energy Output \\
\hline Pretreatment & 0.05 & \\
Pumping from source & 0.03 & \\
Pumping in module & 0.05 & \\
Loss in PX & 0.017 & 0.047 \\
Total energy input & 0.147 & 0.036 \\
Energy output: & 0.194 & 0.026 \\
Oasys-TFC & 0.183 & - \\
Porifera-TFC & 0.173 & - \\
FTS-TFC & 0.133 & \\
HTI-CTA & 0.47 & \\
Maximum specific power & & \\
\hline
\end{tabular}

\subsection{Environmental Benefits of Brine Reject-TSE Salinity Gradient}

Brine reject is the major wastewater stream from the MSF desalination plant and contains around $80 \mathrm{~g} / \mathrm{L}$ of total dissolved solids (TDS), antifoaming, antiscalant and other chemicals [24]. Seawater pollution related to brine discharge has been reported in the literature and yet there is no mitigation action taken to reduce it. Further to its high concentration and chemicals contents, brine reject results in thermal pollution due to the elevated temperature, which is normally from $10^{\circ} \mathrm{C}$ to $15^{\circ} \mathrm{C}$ higher than that of seawater. Despite all concerns associated with brine reject discharge to the sea, this wastewater stream has tremendous osmotic energy that could be harvested by suitable energy, such as the PRO process, for power generation. This will not only reduce the negative impact of brine reject on the environment but also convert a wastewater stream into a source of renewable energy. Typically, the PRO process requires a source of feed solution to pair with a draw solution for power production. In arid and semi-arid regions, freshwater and groundwater resources are rare and impossible to find on a continuous basis. Nevertheless, most countries in the Middle East and in the Gulf Community Council (GCC) area generate large quantities of tertiary treated sewage effluent (TSE) that has low salinity, around $2 \mathrm{~g} / \mathrm{L}$ [25]. Several GCC countries discharge large amounts of TSE to seawater or evaporation ponds, that could be instead coupled with brine reject as a salinity gradient source in the PRO process. Coupling the brine reject with TSE as a salinity gradient resource for the PRO process will achieve a number of benefits that include:

1. To reduce the impact of the MSF desalination plant that is associated with brine reject discharge to seawater as it will be the DS of the PRO process.

2. To reduce the environmental impact of TSE discharge to seawater or send to evaporation ponds that would cause health problems.

3. To convert wastewater streams into a renewable energy source when coupled together in the PRO process.

A successful PRO system will be able to generate energy from mixing the brine reject with TSE and also reduce the concentration and volume of the brine reject and TSE, respectively. Based on the performances of the PRO membranes listed in Table 3, the concentration and dilution percentage of the brine reject draw solution was calculated to estimate the PRO feasibility in reducing the environmental influence of brine reject discharge to seawater. The concentrations of brine reject and TSE are $1.37 \mathrm{M}$ and $0.027 \mathrm{M} \mathrm{NaCl}$ while the temperature is $40{ }^{\circ} \mathrm{C}$ and $25^{\circ} \mathrm{C}$, respectively.

Figure 5 shows the concentration and percentage dilution of brine reject after the PRO process for discharge to seawater. For all membranes, the concentration of brine reject decreased in the PRO module of $1 \mathrm{~m}$ long (Figure $5 \mathrm{a}$ ). For the Oasys membrane, the concentration of brine reject decreased by $39 \%$ (Figure $5 \mathrm{~b}$ ), from $80 \mathrm{~g} / \mathrm{L}$ to $49 \mathrm{~g} / \mathrm{L}$, at the end of the PRO process. Indeed, the concentration of seawater 
in the GCC region is about $45 \mathrm{~g} / \mathrm{L}$ [15], which is close to the concentration of the diluted brine reject from the Oasys membrane. Similarly, the concentration of brine reject treated by the Porifera membrane was close to that of seawater concentration. The PRO process achieved $37 \%$ dilution in the PRO process, reducing the concentration of brine reject from $80 \mathrm{~g} / \mathrm{L}$ to $50.71 \mathrm{~g} / \mathrm{L}$. TFS membrane has achieved 35\% dilution of brine reject at the end of the PRO process and was able to reduce the concentration from $80 \mathrm{~g} / \mathrm{L}$ to $52.36 \mathrm{~g} / \mathrm{L}$, which is slightly higher than the concentration of seawater. Amongst all the FO membranes tested in this study, the HTI membrane's performance was the least successful, achieving $27 \%$ dilution of the concentration of brine reject (from $80 \mathrm{~g} / \mathrm{L}$ to $58.77 \mathrm{~g} / \mathrm{L}$ ). The low coefficient of water permeability of the HTI membrane is the main reason for the unsatisfactory dilution of the brine reject and hence, high-water permeability membranes, such as TFC membranes, are recommended.

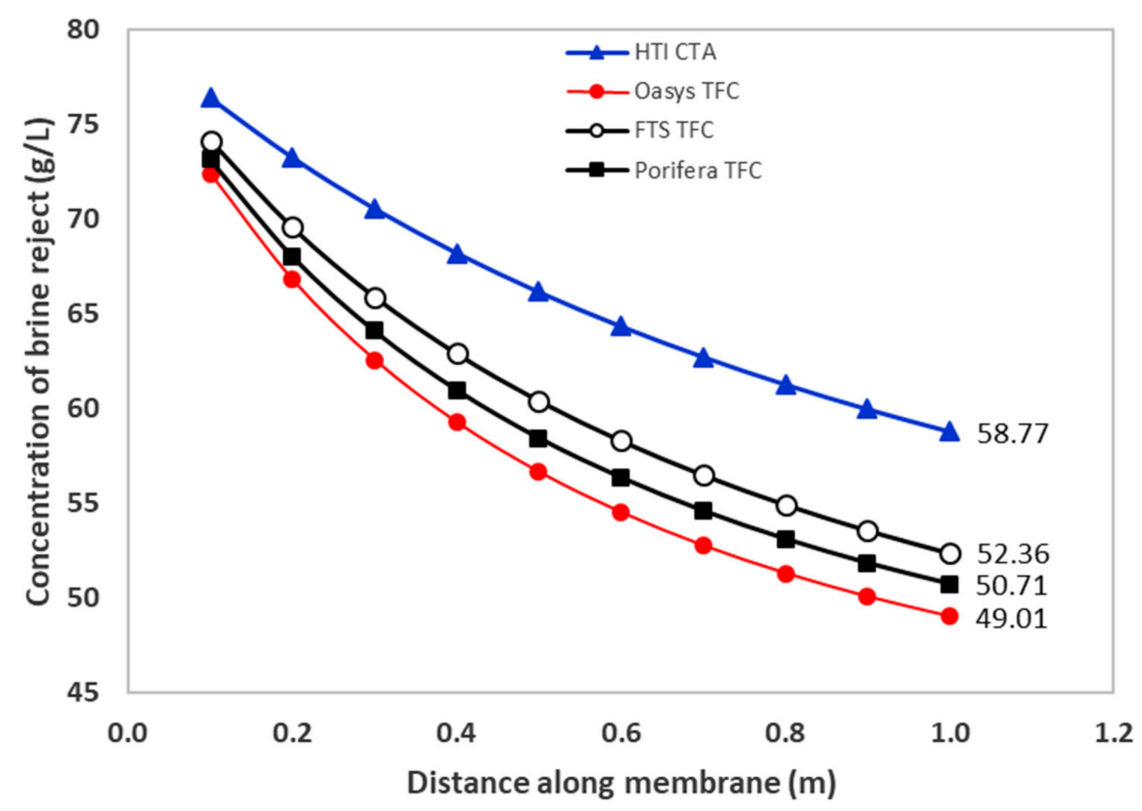

(a)

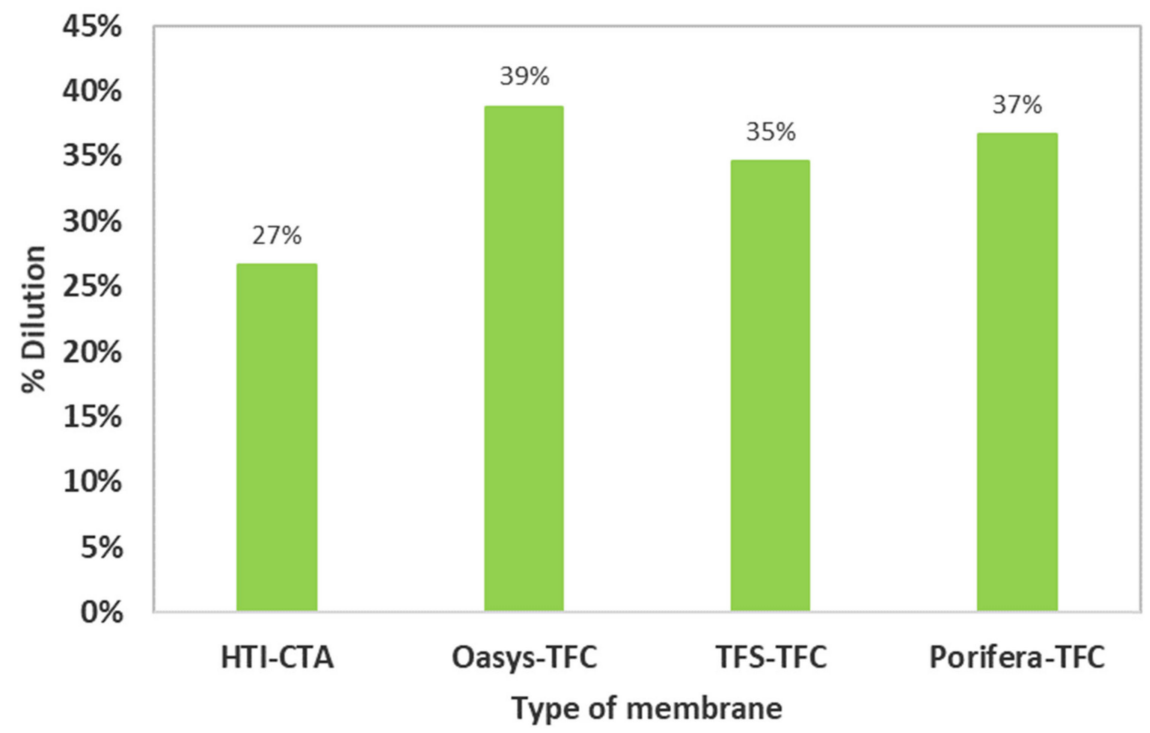

(b)

Figure 5. Effect of pressure retarded osmosis on the the brine reject: (a) Concentration of brine reject after the PRO process for discharge to seawater; (b) the percentage of dilution of brine reject after the PRO process. 
In addition to concentration, the elevated temperature of the brine reject is responsible for thermal pollution when discharged to seawater without further treatment. Typically, the temperature of brine reject is from $10{ }^{\circ} \mathrm{C}$ to $15^{\circ} \mathrm{C}$ higher than that of seawater, resulting in undesirable environmental consequences when discharged. A mass balance of the flow rates and temperatures of draw solution and permeate was performed to calculate the temperature of diluted brine reject at the end of the PRO process:

$$
Q_{D i} \cdot T_{D i}+Q_{p} \cdot T_{p}=Q_{D o} \cdot T_{D o}
$$

where, $Q_{p}$ and $T_{p}$ are the flow rate and temperature of permeate solution, $T_{D i}$ is the DS temperature before dilution in the PRO process, and $T_{D o}$ is the DS temperature after the dilution in the PRO process. Equation (4) was applied to calculate the temperature of the DS after the PRO process. Results reveal that the temperature of the diluted brine reject decreased after the PRO process. The temperature of the diluted brine reject treated by the HTI membrane decreased from $40{ }^{\circ} \mathrm{C}$ to $36{ }^{\circ} \mathrm{C}$ after the PRO process. For the rest of the membranes tested here, a higher decrease in the temperature of brine reject was achieved after the PRO process. For example, the temperature of brine reject treated by the Oasys membrane was $34.2{ }^{\circ} \mathrm{C}$ after the PRO process. Porifera membrane of a high-water permeability coefficient achieved almost a similar dilution to that of the Oasys membrane, reducing the temperature of brine reject from $40^{\circ} \mathrm{C}$ to $34.5^{\circ} \mathrm{C}$ after the $\mathrm{PRO}$ process. Brine reject treated by the FTS membrane experienced a tangible reduction in temperature, from $40{ }^{\circ} \mathrm{C}$ to $34.8^{\circ} \mathrm{C}$, after the PRO process.

Generally, the results demonstrated the feasibility of the PRO process not only to dilute the concentration of brine reject but also to reduce its temperature after the treatment. The reduction in the concentration of the brine reject was between $27 \%$ and $39 \%$; the latter percentage was accomplished in the PRO process with the Oasys membrane. The same membrane achieved the highest reduction in the temperature of the brine reject after the PRO treatment, $34.2^{\circ} \mathrm{C}$. A PRO membrane of high permeabilities such as Oasys and Porifera is recommended for applications in the PRO process for their high performance. The Fluid Technology Solution Company (USA) supplies the CTA membrane for the FO membrane but unfortunately, the TFC membranes of high-water permeability are not always available in stocks. Future work should also concern PRO membrane development of high-water flux and tolerance to hydraulic pressure. New technologies such as nanoparticles incorporation in membrane fabrication could help to develop such a PRO membrane of high permeability and excellent mechanical strength.

\section{Conclusions}

The PRO process was proposed for power production and mitigating the environmental impact of brine reject on seawater. Brine reject and tertiary treated sewage effluent (TSE) was the draw and feed solutions. These wastewater streams are controversially discharged to seawater without further treatment. The study demonstrated the feasibility of the PRO process to produce energy in the PRO process using a brine reject-TSE salinity gradient source. The net specific power generation in the PRO process was strongly affected by the type of the PRO membrane used in the process. TFC membranes such as Oasys and Porifera outperformed the TFS and HTI membranes with low water permeability coefficients. The maximum net energy output achieved in the PRO process using the Oasys membrane was $0.047 \mathrm{kWh} / \mathrm{m}^{3}$. Furthermore, the concentration of brine reject was reduced from $80 \mathrm{~g} / \mathrm{L}$ before the PRO process to about $49 \mathrm{~g} / \mathrm{L}$ after the PRO process. This demonstrated the capability of the PRO process to reduce the impact of high salinity brine reject and mitigate its environmental impact on seawater. The PRO process was also able to reduce the temperature of brine reject, which is responsible for the thermal pollution of seawater, from $40{ }^{\circ} \mathrm{C}$ to $34.2^{\circ} \mathrm{C}$ after the PRO process. The PRO process provides a promising source for renewable energy in the region of the Gulf Corporation Council in addition to the mitigation of the environmental effects of the MSF desalination plant. Future work will focus on laboratory testing of the PRO process for power generation from brine reject-TSE salinity gradient resource. 
Author Contributions: Conceptualization, A.A.; methodology, A.A.; software, A.A.; validation, A.A. and N.A.; formal analysis, A.A.; investigation, A.A.; resources, A.A. and N.A.; data curation, A.A.; writing-original draft preparation, A.A.; writing-review and editing, N.A.; visualization, A.A.; supervision, A.A.; project administration, A.A. All authors have read and agreed to the published version of the manuscript.

Funding: This research received no external funding.

Acknowledgments: Author would like to thanks Professor Endre Nagy and the Journal of Energies for their invitation to contribute in the special issue in pressure retarded osmosis for power production. Author would also acknowledge the support by the Centre of Green Technology at University of Technology Sydney to complete this study.

Conflicts of Interest: The authors declare no conflict of interest.

\section{References}

1. Altaee, A.; Cippolina, A. Modelling and optimization of modular system for power generation from a salinity gradient. Renew. Energy 2019, 141, 139-147. [CrossRef]

2. Altaee, A.; Millar, G.; Zaragoza, G. Integration and Optimization of Pressure Retarded Osmosis with Reverse Osmosis for Power Generation and High Efficiency Desalination. Energy 2016, 103, 110-118. [CrossRef]

3. Thorsen, T.; Holt, T. The potential for power production from salinity gradients by pressure retarded osmosis. J. Membr. Sci. 2009, 335, 103-110. [CrossRef]

4. Altaee, A.; Palenzuela, P.; Zaragoza, G.; AlAnezi, A.A. Single and Dual Stage Closed-Loop Pressure Retarded Osmosis for Power Generation: Feasibility and Performance. Appl. Energy 2017, 191, 328-345. [CrossRef]

5. Nagy, E. A general, resistance-In-Series, salt-and water flux models for forward osmosis and pressure-Retarded osmosis for energy generation. J. Membr. Sci. 2014, 460, 71-81. [CrossRef]

6. Tanaka, Y.; Yasukawa, M.; Goda, S.; Sakurai, H.; Shibuya, M.; Takahashi, T.; Kishimoto, M.; Higa, M.; Matsuyama, H. Experimental and simulation studies of two types of 5-Inch scale hollow fiber membrane modules for pressure-Retarded osmosis. Desalination 2018, 447, 133-146. [CrossRef]

7. Altaee, A.; Zhou, J.; Alanezi, A.A.; Zaragoza, G. Pressure retarded osmosis process for power generation: Feasibility, energy balance and controlling parameters. Appl. Energy 2017, 206, 303-311. [CrossRef]

8. Loeb, S.; Van Hessen, F.; Shahaf, D. Production of energy from concentrated brines by pressure-Retarded osmosis: II. Experimental results and projected energy costs. J. Membr. Sci. 1976, 1, 249-269.

9. He, W.; Wang, Y.; Sharif, A.; Shaheed, M.H. Thermodynamic analysis of a stand-Alone reverse osmosis desalination system powered by pressure retarded osmosis. Desalination 2014, 352, 27-37. [CrossRef]

10. Plata, S.L.; Childress, A.E. Limiting power density in pressure-retarded osmosis: Observation and implications. Desalination 2019, 467, 51-56. [CrossRef]

11. Chen, Y.; Alanezi, A.A.; Zhou, J.; Altaee, A.; Shaheed, M.H. Optimization of module pressure retarded osmosis membrane for maximum energy extraction. J. Water Process Eng. 2019, 32. [CrossRef]

12. Wang, Q.; Zhou, Z.; Li, J.; Tang, Q.; Hu, Y. Investigation of the reduced specific energy consumption of the RO-PRO hybrid system based on temperature-enhanced pressure retarded osmosis. J. Membr. Sci. 2019, 581, 439-452. [CrossRef]

13. Benjamin, J.; Arias, M.E.; Zhang, Q. A techno-Economic process model for pressure retarded osmosis based energy recovery in desalination plants. Desalination 2020, 476, 114218. [CrossRef]

14. Kim, D.I.; Kim, J.; Hong, S. Changing membrane orientation in pressure retarded osmosis for sustainable power generation with low fouling. Desalination 2016, 389, 197-206. [CrossRef]

15. Thabita, M.S.; Hawarib, A.H.; Ammarb, M.H.; Zaidic, S.; Zaragozad, G.; Altaee, A. Evaluation of Forward Osmosis as a Pretreatment Process for Multi Stage Flash Seawater Desalination. Desalination 2019, 461, $22-29$. [CrossRef]

16. Madsen, H.T.; Nissen, S.S.; Muff, J.; Søgaard, E.G. Pressure retarded osmosis from hypersaline solutions: Investigating commercial FO membranes at high pressures. Desalination 2017, 420, 183-190. [CrossRef]

17. Blandin, G.; Vervoort, H.; Le-Clech, P.; Verliefde, A.R.D. Fouling and cleaning of high permeability forward osmosis membranes. J. Water Process Eng. 2016, 9, 161-169. [CrossRef]

18. Bui, N.N.; Arena, J.T.; McCutcheon, J.R. Proper accounting of mass transfer resistances in forward osmosis: Improving the accuracy of model predictions of structural parameter. J. Membr. Sci. 2015, 492, 289-302. [CrossRef] 
19. Cath, T.Y.; Elimelech, M.; McCutcheon, J.R.; McGinnis, R.L.; Achilli, A.; Anastasio, D.; Brady, A.R.; Childress, A.E.; Farr, I.V.; Hancock, N.T.; et al. Standard Methodology for Evaluating Membrane Performance in Osmotically Driven Membrane Processes. Desalination 2013, 312, 31-38. [CrossRef]

20. Ghaffari, A.; Ahmad Rahbar-Kelishami, R. MD simulation and evaluation of the self-Diffusion coefficients in aqueous $\mathrm{NaCl}$ solutions at different temperatures and concentrations. J. Mol. Liq. 2013, 187, 238-245. [CrossRef]

21. Wang, Z.; Tang, J.; Zhu, C.; Dong, Y.; Wang, Q.; Wu, Z. Chemical cleaning protocols for thin film composite (TFC) polyamide forward osmosis membranes used for municipal wastewater treatment. J. Membr. Sci. 2015, 475, 184-192. [CrossRef]

22. Altaee, A.; Ismail, A.F.; Sharif, A.; Zaragoza, G. Dual stage PRO process: Impact of the membrane materials of the process performance. Desalin. Water Treat. 2016, 57, 6172-6183. [CrossRef]

23. Achilli, A.; Cath, T.Y.; Childress, A.E. Power generation with pressure retarded osmosis: An experimental and theoretical investigation. J. Membr. Sci. 2009, 343, 42-52. [CrossRef]

24. Panagopoulos, A.; Haralambous, K.J.; Loizidou, M. Desalination brine disposal methods and treatment technologies-A review. Sci. Total Environ. 2019, 693. [CrossRef] [PubMed]

25. Al-Zubari, W.K. Towards the establishment of a total water cycle management and re-Use program in the GCC countries. Desalination 1998, 120, 3-14. [CrossRef]

(C) 2020 by the authors. Licensee MDPI, Basel, Switzerland. This article is an open access article distributed under the terms and conditions of the Creative Commons Attribution (CC BY) license (http://creativecommons.org/licenses/by/4.0/). 